\title{
Health Care Policy and Reform-Case Study on Liberia Tuberculosis among Childbearing Age Women
}

\author{
David M. Seward \\ School of Public Administration, Huazhong University of Science and Technology, Wuhan, China \\ Email: sewarddavid81@gmail.com
}

How to cite this paper: Seward, D.M. (2021) Health Care Policy and Reform-Case Study on Liberia Tuberculosis among Childbearing Age Women. Health, 13, 975-994.

https://doi.org/10.4236/health.2021.139074

Received: July 29, 2021

Accepted: September 13, 2021

Published: September 16, 2021

Copyright $\odot 2021$ by author(s) and Scientific Research Publishing Inc. This work is licensed under the Creative Commons Attribution-NonCommercial International License (CC BY-NC 4.0). http://creativecommons.org/licenses/by-nc/4.0/

\begin{abstract}
Objective: Liberia health care needs to focus on addressing this disease called Tuberculosis among childbearing age women in Liberia and the world; focusing on women's health governance of Liberia should involve these three sets of actors to control a disease outbreak. The first set of state actors, including politicians, policymakers, and other government officials, need to provide health care education in every part. The public sector health bureaucracy comprising the health ministry, health, social insurance agencies, public pharmaceutical procurement and distribution entities, etc., is central. Still, non-health public sector actors also play a role. Methods: The researcher used the questionnaire method as the main instrument for the study. Results: This survey indicates that $48 \%$ of those responding to health education can reduce TB among childbearing age women showed that education could minimize the spread of TB. $25 \%$ can improve economic status. $27 \%$ said it could reduce the illiteracy rate. The instruments used were positively related to the topic to obtain the needed findings. This set comprises public, private, should not be-for-profit individuals and groups that deliver health services and organizations that support service provision: medical training institutions, health insurance agencies, the pharmaceutical industry. Health service delivery can be presenting from the health system perspective, with inputs, processes, outputs, and outcomes. WHO're Systems Thinking for Health Systems Strengthening explaining that service delivery includes "effective, safe and quality personal and non-personal health interventions that are providing to those in need, when and where needed (including infrastructure), with minimal waste of resources". Conclusion: Inputs for a sound health system, the need for health care delivery include financial resources, competent health care staff, adequate physical facilities and equipment, essential medicines and supplies, current clinical guidelines, and operational policies.
\end{abstract}




\section{Keywords}

Tuberculosis, Childbearing Age Women, Health Care, Diseases, Politicians, Policymakers, Effective, Safe, Quality

\section{Introduction}

TB's prevalence among childbearing age women in the TB Annex is critical regarding its gravity and intensity. The incidence of TB disease is the number of new cases developing in a population during a year. It has been estimating that, in the absence of TB control measure, a 1\% Annual Risk of TB Infection (ARTI) roughly corresponds to an incidence of 50 cases of smear-positive TB and 61 other cases of TB per 100,000.00 (WHO, 1998).

WHO updates each country's incidence figures annually, and for Liberia (WHO, 2005), the expected yearly incidence of pulmonary smear-positive TB is $108 / 100,000$ population. With an estimated population of 3.3 million (2005). "The growing burden of TB, HIV through World Health Organization, control mensural, that is helping Liberians to prevent TB" [1] [2]. The total number of new smear-positive pulmonary TB every year in 3564 cases and 4686 other TB cases, a total of more than 8000 new patients of all kinds of TB annually. For several decades in Liberia, TB has hindered a vast number of childbearing age women. Most women who were affected by the disease are direct liabilities to their families and unable to sustain themselves, according to the 2008 World Health Organization report. The paper, therefore, investigates one aspect of this significant problem; the Prevalence of Tuberculosis among childbearing age women in Montserrado, TB Annex, as a case study specifically.

Universally, the prevalence of Tuberculosis among childbearing age women is the number one infectious killer of women globally. Worldwide, women bear a disproportionate burden of poverty, ill-health, malnutrition, and disease. Not surprisingly, Tuberculosis, a condition associated with poverty and marginalization, also disproportionately affects women. This year, 1 million women will die, and 2.5 million, mainly between 15 and 44, become sick from the disease [3] [4]. "World Health Organization, and World Bank" report TB strikes women in their prime child-rearing and earning years. It has a devastating impact on families as a mother's wellbeing is intimately linked to her children's wellbeing. Study after study has shown that investing in women's health is the most effective strategy a country can pursue to lift itself out of poverty according to World Bank (WB), World Health Organization (WHO), and Harvard report source 2008 [5] [6].

In Africa, TB is a leading cause of HIV-related morbidity and mortality. According to a World Bank impact study released in Africa [7] [8], TB threatens public health achievements in women's health and HIV awareness in 2007. Furthermore, given the high rates of HIV infection among women-who make up 
$61 \%$ of Africa's population-they are the most at risk of contracting TB and developing drug-resistant strains of the disease.

This paper puts forward and addresses the prevalence rate of Tuberculosis, commonly called $\mathrm{TB}$, among childbearing women, which is slowly eating up the fabric of the sector of our working population in Liberia, women of childbearing age. TB is one of the most common opportunistic infections in HIV patients and a leading cause of death globally, including in Liberia.

Besides the social stigma associated with this disease, which cannot be overemphasized, there are cases where it has become a terminal illness for people. Though TB, a known opportunistic disease for HIV infection, has been intensely battled against by the Ministry of Health and Social Welfare according to an assessment taken 1997 (UNICEF-Liberia 1997), [9] [10], it seems that the impact of this battle has not been. Because more childbearing women, particularly in the hinterland, continue to develop the disease (TB). What is responsible for this is the concern of the researcher.

Some of the worst legacies left behind by the fourteen (14) years of the civil crisis in Liberia include deadly and highly contagious diseases like TB, which requires urgent attention. TB, an opportunistic illness for HIV infection, has shown a marked increase among childbearing age women. The need for an educational program with financial help from an international organization and Government support through the national budget. UNAIDS, and WHO [11] [12]. The major problem in treating the disease is the lack of patients' compliance with medication regimens, a primary contributor to the emergence of drug-resistant strains. Some of these resistant strains apply to every anti-tubercular drug available, as indicated by the TB Annex in Congo Town, which gives the infection ratio for men to women as 2:1. However, these superficial relationships may not be valid if TB control intervention has been functioning for years to reduce the period of infectiousness of smear-positive cases. On the other hand, in a civil war with refugees, displaced and malnourished people living in crowded living to disease may be rapid if standards are not implementing [13]. The high fatality rate of this disease, coupled with the socio-economic problems of society, has prompted the researcher to investigate TB's prevalence among childbearing age women.

Figure 1 presents Liberia ministry of health and social welfare, organizational structure.

The three branches of the Government of Liberia are Legislative, Executive, and Judicial; the research will focus on the Legislative branch, which has three primary responsibilities of oversite, lawmaking, and representation. The Legislative-Makes laws (comprised of the House of Representatives and Senate) Executive-Implements the rules (president, vice president, and Cabinet, agencies) Judicial-Interprets the laws (Supreme Court and other courts). The committee on health in both houses of the legislative body has oversite responsibility to make sure things are going the right way. They have the power to help the Liberian people have a sound health care system in the country. 


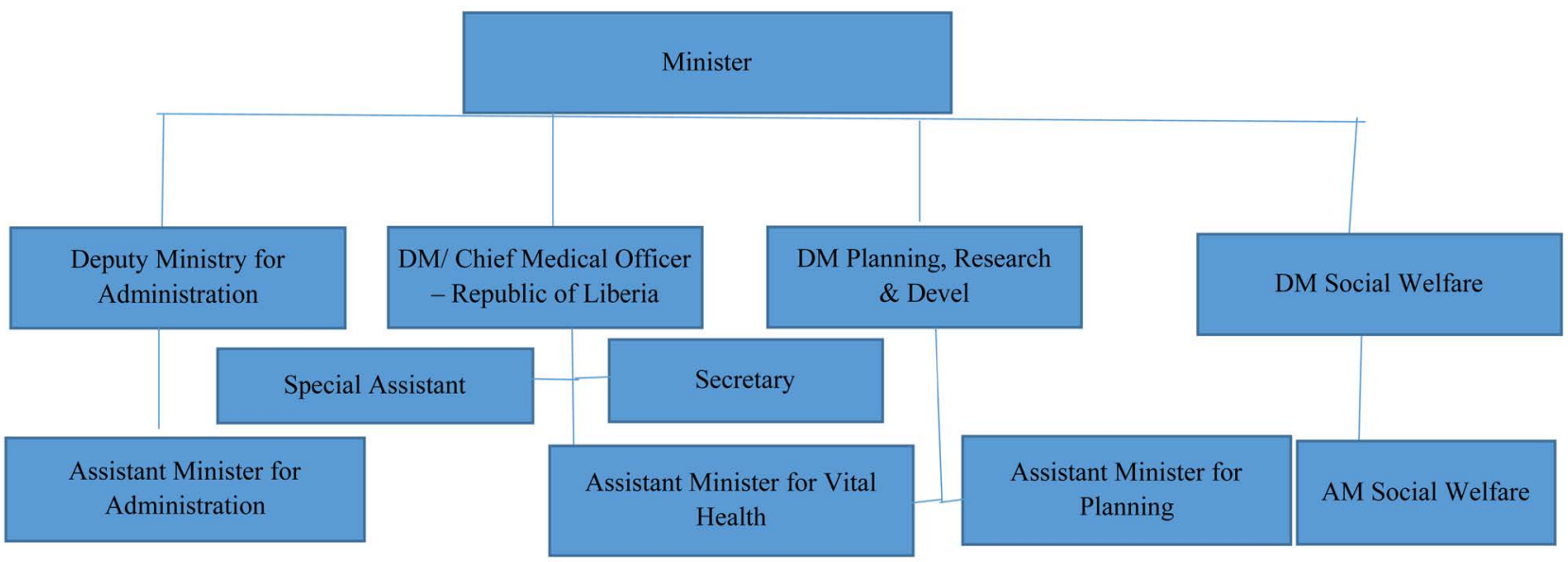

Figure 1. Ministry of health and social welfare, organizational structure.

They have the right to call the Minister of health to answer questions on health issues in Liberia. The lawmaking body in Liberia is causing a serious problem to the health system in Liberia.

The lawmakers are responsible for budgetary allocation for ministries and agencies; see how much is allocating for Liberia's health sector. Can this amount help us with good health and social welfare? The lawmaking body in Liberia is causing a severe problem to the health system in Liberia for examples look below.

Figure 1 Inlostrite Liberia Ministry of Health and Social Welfare, Organizational Structure, and Figure 2 shows the budget allotment for the health sector of Liberia 2020/202. Can this amount make an impact in our health sector?

\subsection{Policy Objectives}

The following objectives are to formulate. The Ministry of Health and Social Welfare must reform the sector to effectively deliver quality health and social welfare services to the people of Liberia. The $\mathrm{MOH} \& \mathrm{SW}$ is dedicating to equitable, accessible, and sustainable health promotion and protection and the provision of comprehensive and affordable health care based on limited information accruing from the situation analysis, which summarizes the health challenges currently facing Liberian people.

Why Policymakers, on the one hand, do not see the reason to use the oversite power in improving the health sector of Liberia; on the other hand, some politicians have the resources to help the National Government enhance the health care system with medicines, education and help with the professional worker to:

- Improved maternal health education in all counties

- Improved child health protection for every child

- Increased equitable access to quality health care services in all counties

- Improved prevention, control, and management of major diseases

- Improved nutrition status education in all school 
SECTION 3: SECTORIAL AND ECONOMY CLASSIFICATION:

The Fiscal Year 2020/2021 Budget as presented is as follows in sectorial and economy classification:

\begin{tabular}{|l|l|}
\hline SECTORIAL CLASSIFICATION & FY 2020/2021 BUDGET \\
\hline Public Administration Sector & $\$ 179,752,695$ \\
\hline Municipal Government Sector & $\$ 27,587,800$ \\
\hline Transparency and Accountability Sector & $\$ 26,168,621$ \\
\hline Security and Rule of Law Sectors & $\$ 79,374.986$ \\
\hline Health Sector & $\$ 66,922,369$ \\
\hline Social Development Services Sector & $\$ 10,990,282$ \\
\hline Education Sector & $\$ 77,392,93$ \\
\hline Energy and Environment Sectors & $\$ 12,270.605$ \\
\hline Agriculture Sector & $\$ 6,425,415$ \\
\hline Infrastructure and Basic Services Sector & $\$ \$ 39,479,584$ \\
\hline Industry and Commerce Sectors & $\$ 8,540,523$ \\
\hline TOTAL & $\mathbf{\$ 5 3 5 , 4 5 2 , 1 7 3}$ \\
\hline
\end{tabular}

Figure 2. Presents the budget allotment for the health sector of Liberia 2020/2021.

Increased access to quality social welfare services but are using these as political tools for their reelections bits. As baseline data is currently inadequate, the MOH \& SW must, for the time being, rely on estimates, projections, and qualitative formulations. However, implementation control put in place TB [14] [15], the Ministry is committed to strengthening information systems so that effective monitoring of operations through quantitative indicators will soon become possible. In formulating the National Health Plan, a set of hands to monitor health sector progress has been developing, emphasizing studying health development from a sector-wide perspective. TOP 10 CAUSES OF DEATH in Liberia 1) Malaria, 2) Diarrheal diseases, 3) Neonatal disorders, 4) Lower respiratory infections, 5) Ischemic heart disease, 6) HIV/AIDS, 7) Stroke, 8) Tuberculosis, 9) Sexually transmitted infections, and 10) In cirrhosis, the researcher will provide data in future research.

Figures 3-5 show the causes of most death in HIV/TB Co-infection Output Indicators and Targets in Liberia and some parts of Africa. Ethiopia, Gambia, Guinea Bissau, Malawi, and Benin.

\subsection{Research Questions}

1) How do childbearing age women come in contact with TB?

2) What are the effects of TB?

3) Which age group of women is positively affected by TB?

4) What is the health delivery system's level of contribution toward preventing $\mathrm{TB}$ among childbearing age women?

5) What impact can health education make in reducing TB among childbearing age women?

RQ 1: Most of the time, childbearing age women in Liberia contact TB from their household; some of the homes have more family members, 10 to 15 persons in a house, they all use identical cups, spoons and eating boards. 
What causes the most death and disability combined?

Communicable, maternal, neonatal, and nutritional diseases

Non-communicable diseases

Injuries

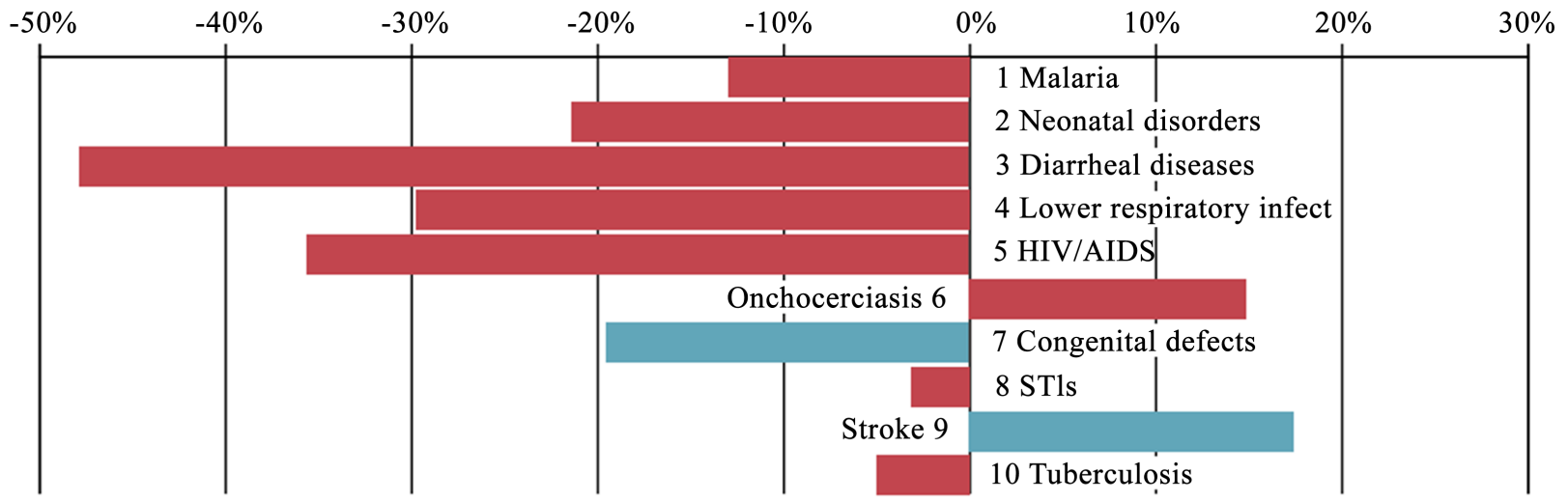

Top 10 causes of death and disability (DALYs) in 2019 and percent change 2009-2019, all ages combined

Figure 3. What causes the most death and disability in Liberia?

\begin{tabular}{|c|c|c|c|c|c|c|c|c|}
\hline \multirow[b]{2}{*}{ Indicators } & \multirow[b]{2}{*}{$\begin{array}{c}2013 \\
\text { Baseline }\end{array}$} & \multirow[b]{2}{*}{2014} & \multicolumn{6}{|c|}{ Targets } \\
\hline & & & 2015 & 2016 & 2017 & 2018 & 2019 & 2020 \\
\hline $\begin{array}{l}\text { Estimated TB cases } \\
\text { (All Forms) }\end{array}$ & & 12,343 & 12,791 & 13,252 & 13,728 & 14,217 & 14,721 & 15,240 \\
\hline $\begin{array}{l}\text { TB Cases expected to be } \\
\text { notified (All Forms) }\end{array}$ & & 9380 & 10,233 & 11,132 & 12,080 & 13,080 & 14,132 & 14,630 \\
\hline $\begin{array}{l}\text { Number }(\%) \text { of TB patients } \\
\text { thatweretested and counseled } \\
\text { for HIVand } \\
\text { know their results }\end{array}$ & $\begin{array}{c}77 \% \\
(5989)\end{array}$ & $\begin{array}{c}79 \% \\
(7410)\end{array}$ & $\begin{array}{c}81 \% \\
(8289)\end{array}$ & $\begin{array}{l}83 \% \\
(9240)\end{array}$ & $\begin{array}{c}85 \% \\
(10,268)\end{array}$ & $\begin{array}{c}87 \% \\
(11,380)\end{array}$ & $\begin{array}{c}88 \% \\
(12,436)\end{array}$ & $\begin{array}{c}90 \% \\
(13,167)\end{array}$ \\
\hline $\begin{array}{l}\text { Number (\%) TB } \\
\text { patients that are HIV positive }\end{array}$ & $16 \%$ & $\begin{array}{c}15 \% \\
(1112)\end{array}$ & $\begin{array}{l}14 \% \\
(1160)\end{array}$ & $\begin{array}{l}13 \% \\
(1201)\end{array}$ & $\begin{array}{l}12 \% \\
(1232)\end{array}$ & $\begin{array}{l}11 \% \\
(1252)\end{array}$ & $\begin{array}{c}10 \% \\
(1244)\end{array}$ & $\begin{array}{c}8 \% \\
(1053)\end{array}$ \\
\hline $\begin{array}{c}\text { Percentage of estimated } \\
\text { HIV-positive incident TB cases } \\
\text { that received treatment for TB } \\
\text { and HIV }\end{array}$ & $33 \%$ & $40 \%$ & $48 \%$ & $56 \%$ & $64 \%$ & $72 \%$ & $80 \%$ & $85 \%$ \\
\hline
\end{tabular}

Figure 4. Liberia what causes the most death and disability combined in.

RQ 2: Itchy skin is one of the potential side effects to be aware of when taking TB medication. Skin rashes, bruising or yellow skin. Upset stomach, nausea, vomiting, diarrhoea or loss of appetite. Lack of feeling or tingling in the hands or feet. Changes in your eyesight mainly change in red or green color vision.

RQ 3: TB is one of the top five killers of women among adult women aged 20 59 years. Four hundred eighty thousand women died from TB in Liberia, including 140,000 deaths among HIV-positive women in Africa. Of the 330,000 
What causes the most death in Africa?

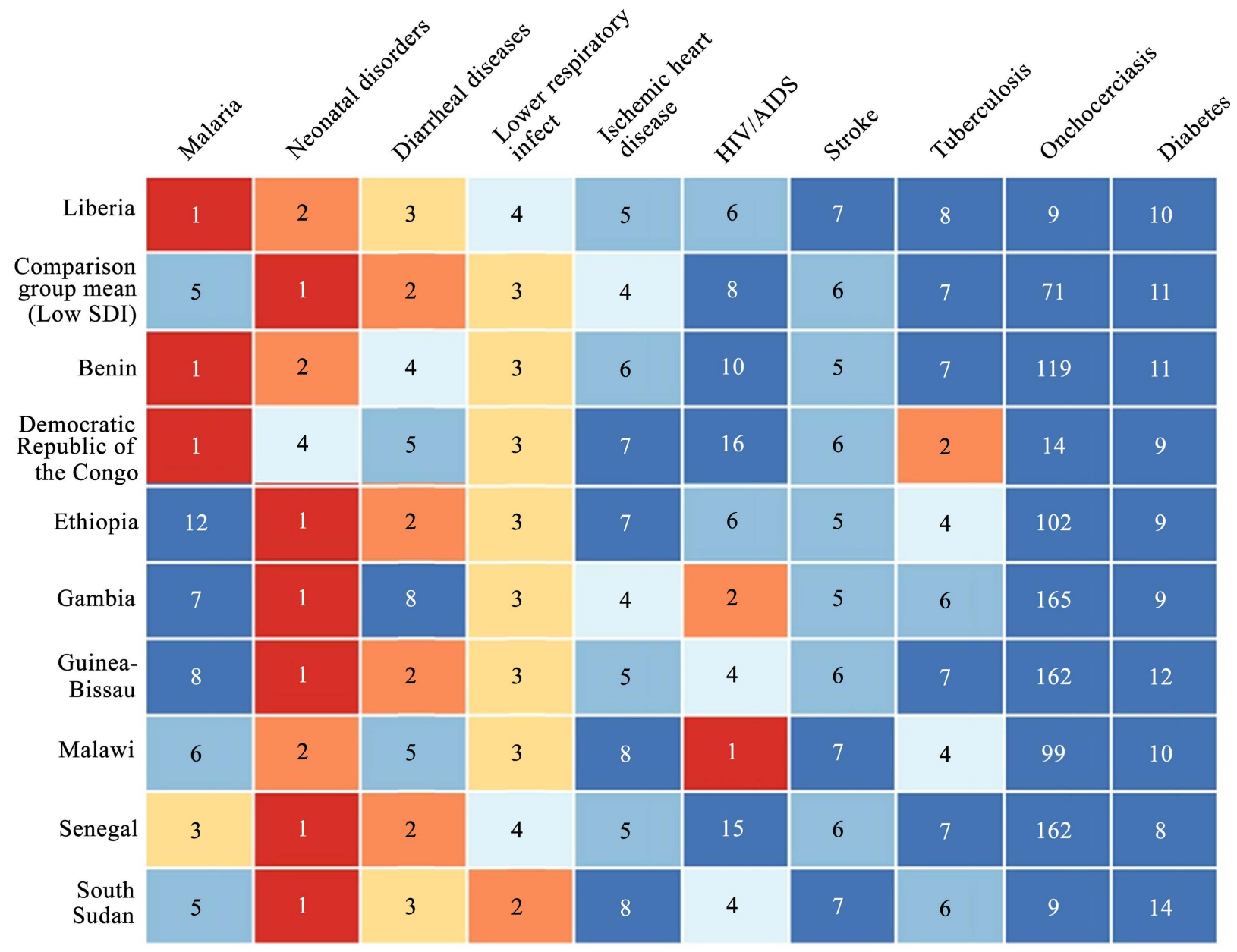

Aqe-standardized DALY rate per 100,000, 2019

Figure 5. HIV/TB co-infection output indicators and targets.

HIV-related TB deaths among adults (age $\geq 15$ ) globally, just over $40 \%$ were among women, accounting for about one-third of all AIDS-related deaths among female adults. Almost 90\% of these HIV-associated TB deaths among women were in Africa. In Africa, TB rates are ten times higher in pregnant women living with HIV than those without HIV infection. Facility-based studies in several high HIV burden settings found TB accounted for 15\% - 34\% of indirect causes of obstetric mortality.

RQ 4: Liberia's health system is facing capacity difficulties in all parts of the country. It is chronically short of human resources, equipment, and drugs. The decentralization policy faces serious challenges, not least of which is the difficulty of finding professional health workers willing to deploy to far-flung areas. How to prevent TB in Liberia? We need health education in every part of Liberia, policymakers to increase the health and social welfare budget. The Government needs to build housing units, outside the city, for treatment and after they are well, they should be taking to their home. 
RQ 5: Health education is critical, and we need it in our society; we need it in our schools, on radio, television and in every community. Risk factors such as diabetes, tobacco smoking, silicosis, alcohol and drug misuse, mental health disorders and malnutrition hamper the fight against TB.

\subsection{Significance of the Paper}

It is essential to study TB's prevalence among childbearing age women because it will help us understand why the majority is occurring and what we can do to remedy it. The discussion and a solution sought, women involved will eventually become liabilities to society [16]. Meanwhile, being liabilities to society leaves an economic problem of income generation and utilization. Income-earning will rest on a few persons' shoulders to manage a group of people. The sick women already have underage children and all other extended liabilities and those likely affected by their mothers.

\section{Discussion: What Is Tuberculosis?}

Tuberculosis (TB) is a systemic infectious disease caused by mycobacterium tuberculosis, which grows best in areas of the body that have lots of blood and oxygen. TB most often affects the respiratory system and other parts of the body, such as gastrointestinal genitourinary tracts, bones, joints, nervous system, lymph nodes, and the skin may also be infecting. Almost every organ in the body can be affected, but the lungs' involvement (pulmonary Tuberculosis) accounts for more than $80 \%$ of tuberculosis cases. When Tuberculosis affects the lungs, it is called pulmonary TB, but when TB spreads to other parts of the body, it is called extrapulmonary TB. Tuberculosis was a common and deadly infectious disease that luckily affected fewer people since the United States now has a vaccine. Unfortunately, there are still a high number of people dying of this infection yearly. Tuberculosis in Liberia, which has the human organism of our health system, the Government and the National Leprosy and TB Control Program is yet to improve the living standards of the majority of the typical Liberian woman affected by TB Bacilli.

According to history, most infected persons remain entirely well without manifestation of the TB disease during their life span. However, not everyone who is exposed will contract TB. Some also have asymptomatic latent tuberculosis infections. One in ten of these latent infections will develop into active TB. Untreated Tuberculosis will kill more than half of people infected with it, so treatment is significant if you know or suspect you have it. The tuberculin hypersensitivity can be various methods that introduce protein into the test subject's tissue.

Additionally, the disease probably Tuberculosis was known as early as 1,000 BC. Hippocrates described the symptoms of a disorder called Phthisis, "meaning to waste away", and recognizes nodules (Phymata) of the lung as a feature of the disease. Such nodules were termed "tubercular" in Latin called "tubercles" when 
they became recognized as a pathologic characteristic of the disease. Tuberculosis was first applying to the disease's clinical and pathological description in 1834.

The causative micro-organism discovered by Dr. Robert Kock in 1882 became known as the "tubercle bacillus". In Liberia, the bacteria were first found in early 1900 by Dr. J. N. Togba and Dr. H. Nehemiah Cooper. Moreover, according to the National Leprosy/TB Control Program, statistical reports show Liberia's caseload estimates 8000 - 10,000 patients. The prevalence is four per thousand (4/1000). Liberia has just emerged from the trauma of civil war and economic deprivations, including food, shelter, overcrowded in communities, etc.

\subsection{Risk of Infection}

Three factors determine an individual's risk of infection: the concentration of droplets in contaminated air, the length of time he breathes that air, and finally, his infection susceptibility. The highest risk is with close, prolonged, indoor contact with a person with sputum smear-positive TB according to the WHO 1997 Report.

\subsection{Transmission of Infection}

The source of infection is a person with TB of the lungs and who is coughing. Transmission occurs by the airborne spread of infectious droplets and generally indoors, where droplets can stay in the air for a long time. Ventilation removes droplets, and direct sunlight quickly kills the bacilli. The tuberculin skin test, which detects Mycobacterium tuberculosis infection, can measure. Transmission occurs airborne through infection droplets and generally indoors, where droplets can stay in the air for a long time. Ventilation removes the droplets, and direct sunlight quickly kills the bacillus. The disease's onset is usually insidious, lacking energy, weight loss, and persistent cough.

The symptoms do not subside, and the general health of the patient deteriorates. Eventually, as the cough increases, there is much sweating, the patient may have chest pains, there may be blood in the sputum alarming symptoms are cough for three weeks or more without blood, increasing weakness or more with blood, fewer, and shortness of breath (Diff, 1989, P. 54). Patients with pulmonary Tuberculosis and the bacilli are as numerous as to be seen on microscopic examination of sputum specimens are the most infectious cases.

These patients are the main target for control.

Smear-positive Tuberculosis is rarely founding in children, and therefore, with a few exceptions, they do not transmit the disease. Smear negative cases flattering on culture only (or even culture-negative) are about ten times less infectious than those positive by microscopy. Their outcome is more favourable; extrapulmonary TB cases are even less infectious Daniels, 1990 [17]. These adult patients with smear-positive Tuberculosis of the lings are the primary source of infection. They spread the bacilli by coughing (droplet infections) and have to be 
detected and treated. Still, they must be separating from those bacteriological confirmed.

Therefore, infection with HIV destroys the body's immune defence mechanisms and is a significant risk factor for TB development. In a non-HIV infected person, the risk of action from latent infection to disease is $10 \%$ during that person's entire lifetime. In HIV-infected persons, the risk of developing TB is much higher (10 times).

- Three mechanisms appear relevant to the development of HIV-associated TB

- Reactivation of dormant infection

- Progression from recent infection

- Re-infection

TB can occur at any point in the course of the progression of HIV infection.

The risk of developing TB rises sharply with worsening immune status.

Even in situations where there are many HIV/TB patients, the principles of $\mathrm{TB}$ control are the same, but with further consequences and difficulties for health services and Program as;

- Over-diagnosis of sputum smear-negative PTB

- Under-diagnosis of sputum smear-positive PTB (laboratory workload. Huge)

- Low cure rates

- The high mortality rate during treatment

- Increased rate of relapses

\subsection{Control}

The control of TB in Liberia is basing on government intervention with the help of some partners like the World Health Organization (WHO) recommendation, the "Directly Observed Treatment Short" course (DOTS) policy package. The policy includes the Dr. J W. Lee Page 49 following [18] [19],

- Sustained political and financial commitment from Government

- Diagnosis through a quality-assured network of TB sputum microscopy services

- Use of 6 - 8 months' short term chemotherapy for all cases, including direct observation of drug intake at least during the initial intensive phase of treatment (first two to three months of treatment)

- Uninterrupted supply of quality anti-TB drugs

- Effective monitoring standardizing and reporting system

The identification, treatment, and cure of smear-positive cases of pulmonary Tuberculosis are a priority. The diagnosis and remedy of these cases can document the sputum test with a reliable and cheap means.

Recording and reporting statistics on patients diagnosed with TB and their outcomes are essential to assessing the Programme.

Step-by-step strategy with policy to adopted gives priority to quality. In other words, one should not treat many patients before being able to cure a few. Through sufficient coverage of the population with standardized and high-quality TB service, the NLTCP, in collaboration with other health institutions, offers the same 
access to diagnosis, the same treatment accessible to TB patients. To achieve the cure of these patients, their assured by daily supervised therapy during the initial intensive phase preventing defaulting and retrieval of absentees, if necessary. The NLTCP field staff participates in these activities, especially during the monthly supervised ambulatory treatment [19]. The NLTCP conducts its activities through the general health service with established TB treatment units. Screening of suspected TB cases with sputum microscopy and delivering supervised anti-TB treatment during the Intensive phase and monthly in the continuation phase done through partners via Government, mission, and private. This collaboration is also necessary to ensure proper coverage of the country.

The TB Treatment Center should provide:

- Competent staff to assure the screening of suspects; make the diagnosis and deliver the treatment

- Assure the daily supervised treatment during the Intensive phase of treatment. (DOTS)

- Provide laboratory facilities to conduct sputum tests for the suspects and those receiving treatment in the intensive and continuation phases. The laboratory should participate in Quality Control

- Good cooperation with the NLTCP field team to prevent any treatment interruption

- Proper facilities safely store drug materials supplied by the Program and account for them

\section{Diagnostic Methods}

1) The diagnosis of Tuberculosis for control purposes should be easily assessable, reliable, and cheap.

2) The procedures below to formally diagnose Tuberculosis should only be undertaking once the patient has been tactfully questioning and clinical examination thoroughly done. Besides the disease's symptoms, it is essential to verify whether anti-TB drugs were taking previously and, if so, which type and for how long.

The most reliable and cheapest way to diagnose is to find the tubercle bacillus in a smear of the patient's sputum. Sputum is defined as positive if at least $3 \mathrm{AFB}$ are seeing in the smear's 100 oil immersion fields. Three sputum specimens must be collected and examined in two to three consecutive days (spot, early morning, place). PTB + is confirmed when there are at least two positive smear results or when one sputum is positive for AFB in addition to radiographic abnormalities consistent with active FTB WHO 1998 Report Page 253 [20].

One positive smear result does not justify starting TB treatment since the specimen handling errors can never exclude. Smear negative is defined as all three sputum tests are negative for AFB. The laboratory should keep all positive and negative slides for collection for quality assurance.

Although culture is an excellent way to confirm smear-negative patients' diagnosis with a suspect chest X-ray, it requires expensive, sophisticated material 
and skills. It takes several weeks to yield the results.

The tuberculin (Mantoux or Heaf) test has limited clinical work value, especially where Tuberculosis is common. Malnutrition, other conditions that modify the immunity (such as infection with HIV), or Tuberculosis severity can weaken or make the test negative.

The test may help non-BCG-vaccinated children under six years of age, as very suggestive of TB infection. A decision as to whether these children should be treated as TB patients or given chemoprophylaxis based on history contact with a case of infectious Tuberculosis and the signs and symptoms [20].

In most cases of sputum, smear-positive, PTB, and X-ray are not necessary. $\mathrm{X}$-ray is not readily available or affordable, and no X-ray pattern is typical for PTB, especially with underlying HIV infection.

ESR, cell counts, and other blood tests are not specific and constitute an unnecessary charge for the patient. They should not include in routine diagnostic procedures for TB. The body weight before the initial presentation in the clinic is rarely available. In "under-five children," weight charts may exist and provide valuable information to document the loss of weight. Such documents should systematically be asking of the mothers. Although not specific, the body weight at the beginning of treatment is needed to correct drugs and during treatment [21]. It is a cheaper and valuable means to appreciate the effectiveness of the treatment. The presentation of TB patients with HIV infection mainly depends on HIV infection and could broadly be classified as early and late presentation. In the early stages of HIV infection, it is almost indistinguishable from other TB forms, but the display can be atypical in the late stages.

Although detecting HIV positivity is necessary, testing may not always be available. Still, certain clinical features of TB are more common in HIV-positive patients than in HIV-negative TB patients. Some of these differences are:

- Extrapulmonary TB, particularly general lymph nodes enlargement

- Military disease

- Chest X-ray shows less often cavitations but rather meditational lymph nodes or pleural effusion

- Unusual sites, such as the brain, may be involved

- Sputum test may be harmful despite considerable changes in the chest Z-ray

Tuberculosis in late HIV stage infected patients is considering as the first sign of AIDS. When the diagnosis of Tuberculosis, the following characters should let one suspect the positivity of AIDS:

- Generalized lymphadenopathy

- Candida infection (painful white patches of fungus in the mouth)

- Diarrhoea for more than one month

- genital herpes or herpes zoster (shingles)

- If HIV testing is available, the patient should give their consent; they inform them of the reason for the test and the meaning of the results

Remember, the test is always confidential!

Interestingly, during the late President Samuel K. Doe administration, a sur- 
vey was conducted throughout the Republic of Liberia in 1983 by Dr. Elizabeth White (MD), a British national who helped revamp the entire TB Control Program nationwide. She set up treatment centres in rural and urban areas and two (2) major treatment centres in Monrovia. The TB Annex, which was headed by Dr. Simon O. Charles (MD), while Dr. S. K Mathur (MD) directed the Chest Clinic at the John F. Kennedy Medical Center (JFK). Both specialists left due to the Liberian civil crisis. There is currently a resistant strain to the existing drugs at the TB Annex. Some patients at the hospital need further treatment to make up for the kind of recovery necessary. Those drugs are not available for those patients that are leading to death, prolongation of ill health, deterioration of health condition, according to TB Annex Report 2008.

\subsection{Limitation}

In constructing this research, several constraints are encountering. Among them included difficulty in collecting data and setting up the skype of the researcher to get to the respondent of my data. The researcher uses Skype for this work primarily. The researcher was not on the ground to get the principles of patients' confidentiality research. Other difficulties encountered were accessing documentation at places where such research could gather source information.

\subsection{Research Design}

The researcher decided to use survey reading materials design as an appropriate way to achieve the intended objectives. It enables the researcher to seek exact information from all respondents. The questions show the same items.

\subsection{Population}

Monrovia has three thousand five hundred and ninety-one persons affected by twenty-four TB Annex Units. The researcher used one of the twenty-four (24) TB Treatment Centers, the TB Annex located in Congo Town, looking at the importance of this study. The TB Annex has a population of five hundred forty-five (545) affected persons. Out of these numbers of persons, there are two hundred forty-five women and three hundred men. To balance our investigation from a cross-section of patients, a population of two hundred forty-five (245) persons was identified.

\subsection{Sampling/Sample Size}

For adequate and effective investigation on TB prevalence among childbearing age women in the TB Annex situated in Congo town, a total of sixty (60) persons have been randomly selecting for the sole purpose of sampling. Between fourteen (14) to forty-four (44), the women through Skype for a desirable result.

\subsection{Research Instruments}

The researcher used the questionnaire method as the main instrument for the 
study. Questions were developing for the various patients, and the researcher considered closed-ended questions for all the responses to be informing for easy processing and arrangement. The instruments used were positively related to the topic to obtain the needed findings.

\subsection{Data Collected}

The questionnaires were distributed through Skype conversations and delivered to ensure confidentiality. After one week, the researcher collected the data for analysis and interpretation.

\section{Data Analysis and Interpretation}

This section of the health care policy reform presents the issue of the Prevalence of TB among Childbearing Age Women. It analyzes the result gathered from some knowledgeable individuals within the Treatment Unit and the Annex as well.

All data collected during the publication were interpreting and discussed in this paper. We have come up with this paper giving the percentage of people who contributed to the questionnaire from this backdrop. Critical analysis has been may to arrive at the rate as shown in the below data.

This interview is dividing into two parts. Tables 1-3 are views of patients. Table 4 and Table 5 are views of Heath Workers.

Figure 4 indicates that 20 persons interviewed out of sixty, which is $33 \%$, acknowledged they could contact TB through the air, 22 persons, which is $37 \%$, said they do not know, and 18 persons, which is $30 \%$ of 60 persons said that TB could be contacting from the person affected in the house.

Table 1. How do childbearing age women come in contact with TB?

\begin{tabular}{ccc}
\hline Responses & Frequency & Percent \\
\hline TB can be contacted through the air & 20 & $33 \%$ \\
They can contract TB from a person affected in the house & 18 & $30 \%$ \\
Do not know & 22 & $37 \%$ \\
Total & 60 & $100 \%$
\end{tabular}

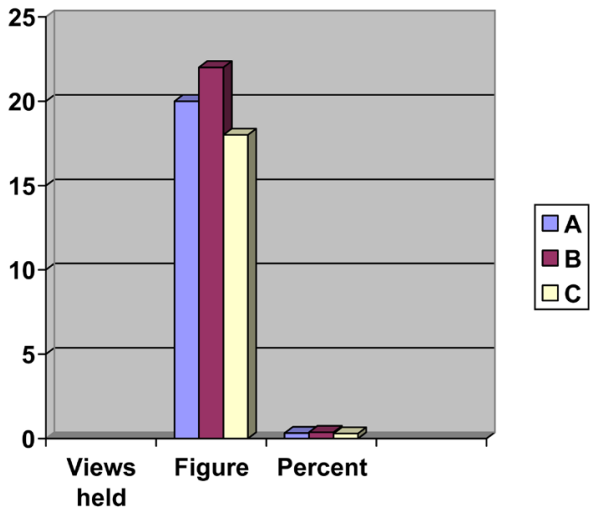


Table 2. What are the effects of TB?

\begin{tabular}{ccc}
\hline Responses & Frequency & Percent \\
\hline Unable to support yourself & 28 & $47 \%$ \\
Being abandon by people & 12 & $20 \%$ \\
Make one helpless & 20 & $33 \%$ \\
Total & 60 & $100 \%$ \\
\hline
\end{tabular}

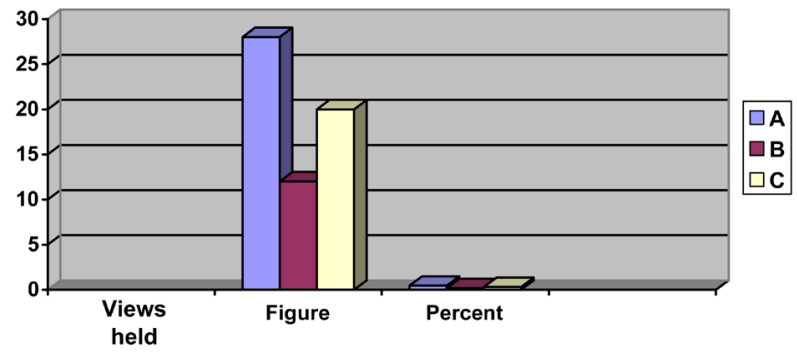

Table 3. The number of respondents interviewed.

\begin{tabular}{cccc}
\hline & Responses & Frequency & Percent \\
\hline A & $15-24$ & 10 & $16 \%$ \\
B & $25-34$ & 24 & $40 \%$ \\
C & $35-60$ & 18 & $30 \%$ \\
D & I don't know & 8 & $14 \%$ \\
& Total & 60 & $100 \%$ \\
\hline
\end{tabular}

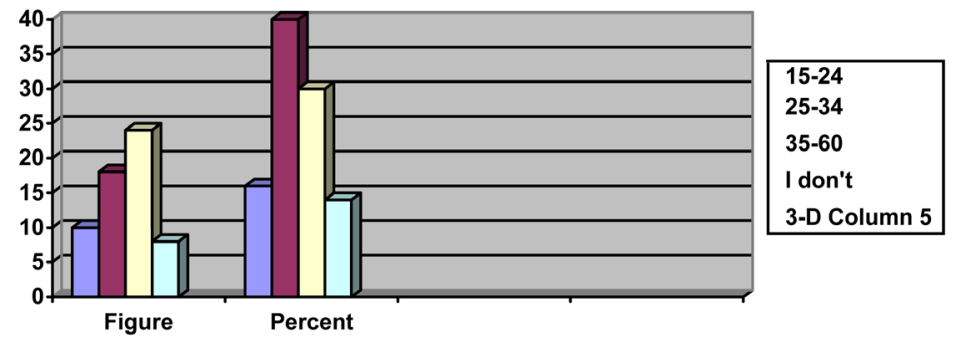

Table 4. Views held about number of persons 60 .

\begin{tabular}{cccc}
\hline & Views Held & F. & $\%$ \\
\hline A & Government provide food & 40 & $66 \%$ \\
B & Provide drugs & 14 & $24 \%$ \\
C & Other NGO provide subsidy & 6 & $10 \%$ \\
& Total & 60 & $100 \%$ \\
\hline
\end{tabular}

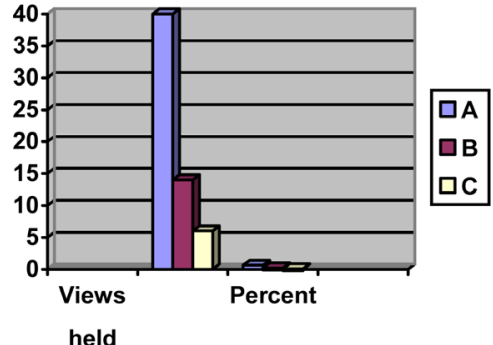


Table 5. Number of persons 60 .

\begin{tabular}{cccc}
\hline & Views Held & F & $\%$ \\
\hline A & Education can minimize the spread of TB & 29 & $48 \%$ \\
B & Improve Economic status & 15 & $25 \%$ \\
C & Reduce illiteracy rate & 16 & $27 \%$ \\
& Total & 60 & $100 \%$ \\
\hline
\end{tabular}

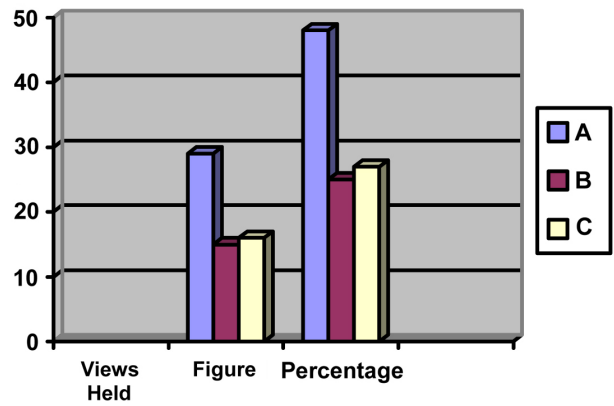

The survey in table two shows that majority of the people are unable to support themselves, representing $47 \%$. The data shows that people are abandoning $20 \%$. 33\% feel they do helpless. Table 2 which age group of women is highly affected with $\mathrm{TB}$ ?

The data collected in table three shows that many of the respondents interviewed said ages between 25 and 34 are highly affected, 40\%. 30\% said ages between 35 - 60 are highly affected. 16\% said ages between $15-24$. To not be bias $14 \%$ said they do not know.

The level of contribution from the Health delivery system toward the prevention of TB among childbearing age women?

The survey shows that the majority of those interviewed, which is $66 \%$, said the Government was responsible for feeding TB-affected victims. $24 \%$ agreed that Government should provide drugs. While $10 \%$ asked NGOs gave subsidy.

Views held about what impact can health education make in reducing $\mathrm{TB}$ among childbearing age women?

This survey indicates that $48 \%$ of those responding to health education can reduce $\mathrm{TB}$ among childbearing age women showed that education could minimize the spread of TB. $25 \%$ can improve economic status. $27 \%$ said it could reduce the illiteracy rate.

The main activities of the strategies are: build the capacity of the HIV/TB Technical Working Group to provide technical guidance and direction [21]. Conduct joint HIV and TB program planning, monitoring and supervisory visits to service delivery sites. Generate demand for HIV and TB services at the community level, including reducing stigma and discrimination. Train clinicians and lab technicians on HIV TB collaborative activities. Screen all PLHIV for TB and refer all suspected cases of TB to the TB program. Provide HCT services to all TB 
cases and refer all HIV positive TB cases to the HIV program for further management. HCT services expanded to all TB Directly Observed Treatment Short Course (DOTS) sites. Prevent stock-out of HIV and TB drugs at treatment facilities. Reduce lost to follow-up.

\section{Case Finding}

Case finding covers all the activities from the identification of suspects to the registration of the diagnosed cases. The assessment findings also indicated frequent stock-out of TB slides, slide boxes, staining reagents, and specimen cups during the assessment year. Therefore, the treatment centres play a vital role at the level of case finding. The case finding's main aim is to diagnose and treat TB cases as early as possible, primarily smear-positive pulmonary (PTB+) cases, because they are the most critical infection sources (Toman K. Tuberculosis, 1979, P. 748).

The following case-finding activities are implementing

- Examine a suspect case of signs and symptoms suggestive of TB

- Examine sputum of all suspect cases by direct microscopy for the presence of acid-fast bacilli (AFB)

Other essential activities, which improve the effectiveness of passive case funding, are:

- Public education is the importance of early self-reporting for examination and treatment

- Training of general health staff in the signs and symptoms of the disease

- They are making reliable treatment centre services accessible to all communities in the country

Pulmonary Tuberculosis should be suspected if a patient presents with the following symptoms:

- Persistent cough for three weeks or more

- Productive cough with or without blood-stained sputum

- Pain in the chest

- Shortness of breath

- Fever of sweating (which may only be present at night)

- Loss of appetite and weight

A patient may not present all the symptoms, but any of them is particularly meaningful if associated with a cough lasting for more than three weeks. The diagnosis is more likely if the patient has been in contact with another tuberculosis patient or with a person presenting similar symptoms.

Moreover, any person who has a chest $\mathrm{x}$-ray examination suggests $\mathrm{TB}$ as a suspect for other medical reasons.

The signs and symptoms of Extrapulmonary Tuberculosis depend mainly on the organ involved. The most common symptoms are:

- Painless swelling of lymph nodes around the neck (lymphadenitis)

- Pain while breathing in, dull lower chest pain, slight cough (pleurisy) 
- Pain and swelling of joints with or without discharging sinus (arthritis)

- Stiff spines, spinal humps or limp on walking or onset of weakness in arms or legs (spondylitis)

Failed to thrive (fever, no weight gain, loss of energy, no response to antibiotics).

\section{Conclusions and Recommendations}

\subsection{Conclusion}

Given the investigation into the problem of the prevalence of Tuberculosis among childbearing age women; a case study at the TB Annex in Monrovia, it is established that:

Based on the data collected and analyzed, it is discovered and affirmed that women are among the most affected by Tuberculosis in Monrovia.

The research also gathered some of the major factors responsible for the prevalence of TB among childbearing age women in Monrovia as follow:

$>$ Living in a poor hygienic environment

Over crowdedness at home

Lack of financial support

Coughing and social stigma

Living self-supported

All of the above factors contribute significantly to the prevalence of TB among childbearing age women in Monrovia.

There should be a mechanism put into place by the central Government and its partners to minimize the spread of the disease by improving the living conditions of the people.

\subsection{Recommendations}

1) According to the survey conducted, nearly most respondents say they do not know how women contact TB with childbearing age. So I strongly recommend that to reduce the spread of $\mathrm{TB}$, there should be health awareness in the communities which require proper training and planning.

2) That the Government should make available the $\mathrm{Tb}$ resistant strain drugs in the country.

3) Because women are caretakers of the homes, women with TB should empower the Government to protect their lives and the lives of their families from contracting the disease.

4) To avoid the spread of TB, the communities need to be aware of early diagnosis of TB utilizing preventive treatment rather than curative treatment.

5) To minimize the rapid spread of $T B$, the Government needs to put a mechanism to follow up on every TB patient to ensure that their drugs are adequately taking to avoid defaulter and relapse.

6) The NLTCP should provide:

- Uninterrupted supply of laboratory material and drugs used for diagnosis 
and treatment of TB;

- Training and retraining of staff;

- Quality Control service to ensure high standards of quality for the bacteriological diagnosis;

- Information on the progress of TB control in the country should be;

- We need to look at other countries' systems on this disease and come up with policies.

\section{Conflicts of Interest}

The author declares no conflicts of interest regarding the publication of this paper.

\section{References}

[1] Corbett, E.L., Watt, C.J., Walker, N., Maher, D., Williams, B.G., Raviglione, M.C., et al. (2003) The Growing Burden of Tuberculosis: Global Trends and Interactions with the HIV Epidemic. Archives of Internal Medicine, 163, 1009-1021. https://doi.org/10.1001/archinte.163.9.1009

[2] Kochi, A. (1991) The Global Tuberculosis Situation and the New Control Strategy of the World Health Organization. Tubercle, 72, 1-6. https://doi.org/10.1016/0041-3879(91)90017-M

[3] World Health Organization (1997) Treatment of Tuberculosis: Guidelines for National Programmes.

[4] Murray, C.J.L., Styblo, K. and Rouillon, A. (1990) Tuberculosis in Developing Countries: Burden, Intervention, and Cost. Bulletin of the International Union against Tuberculosis and Lung Disease, 65, 2-20.

[5] Suarez, P.G., Watt, C.J., Alarcon, E., Portocarrero, J., Zavala, D., Canales, R., et al. (2001) The Dynamics of Tuberculosis in Response to 10 Years of Intensive Control Effort in Peru. The Journal of Infectious Diseases, 184, 473-478. https://doi.org/10.1086/322777

[6] Floyd, K., Blanc, L., Raviglione, M. and Lee, J.W. (2002) Resources Required for Global Tuberculosis Control. Science, 295, 2040-2041. https://doi.org/10.1126/science.1069771

[7] Sachs, J. (2001) Macroeconomics and Health: Investigating in Health for Economic Development. World Health Organization, Geneva.

[8] World Health Organization (2003) Global Tuberculosis Control: Surveillance, Planning, Financing. WHO Report, Geneva.

[9] The World Bank Group (1979) Haiti Data Profile. 12-8-Toman K. Tuberculosis, P 7482003.

http://devdata.worldbank.org/external/CPProfile.asp?CCODE=HTI\&PTYPE=CP

[10] (2002) UNAIDS Joint United Nations Programme on HIV/AIDS.

[11] Drummond, M.F., O’Brien, B., Stoddart, G.L. and Torrance, G.W. (1997) Methods for the Economic Evaluation of Health Care Programs. Oxford University Press, New York, 2.

[12] Weinstein, M.C., Siegel, J.E., Gold, M.R., Kamlet, M.S. and Russell, L.B. (1996) Recommendations of the Panel on Cost-Effectiveness in Health and Medicine. JAMA, 276, 1253-1258. https://doi.org/10.1001/jama.276.15.1253

[13] Ainsworth, M., Koda, G., Lwihula, G., Mujinja, P., Over, M., Semali, I., et al. (1992) 
Measuring the Impact of Fatal Adult Illness in Sub-Saharan Africa-An Annotated Household Questionnaire. Standards Measurements Study Working Paper No. 90, The World Bank, Washington DC, 762-768.

[14] Vaca, J., Peralta, H., Gresley, L., Cordova, R., Kuffo, D., Romero, E., et al. (2005) DOTS Implementation in a Middle-Income Country-Development and Evaluation of a Novel Approach. International Journal of Tuberculosis and Lung Disease, 9, 521-527. http://www.worldbank.org/data/countrydata/countrydata.html

[15] World Health Organization (2003) Global Drug Facility First-Line Tuberculosis Drugs \& Formulations Currently Supplied/Provided by the Global TB Drug Facility. http://stoptb.org/gdf/drugsupply/drugs_available.asp

[16] The World Bank Group (2004) Achieving the MDG's and Related Outcomes: A Framework for Monitoring Policies and Actions. FTB WHO 1998 Report, 253. http://www.developmentgoals.org

[17] Donald, P.R. (1999) Children and Tuberculosis: Protecting the Next Generation? Tuberculosis Progress Report, 353, 1001-1002.

[18] Levy, M., Reyes, H. and Coninx, R. (1999) Overwhelming Consumption in Prisons: Human Rights and Tuberculosis Control. Health and Human Rights, 4, 166-191. https://doi.org/10.2307/4065172

[19] Donald, P.R. (1999) Children and tuberculosis: protecting the next generation? (Tuberculosis Progress Report). The Lancet Interactive.

[20] Levy, M., Reyes, H. and Coninx, R. (1999) Overwhelming Consumption in Prisons: Human Rights and Tuberculosis Control. Health and Human Rights, 166-191.

[21] Rangan, W. and Uplekar, M. (1999) Socio-Cultural Dimensions in Tuberculosis Control. In: Porter, J.D.H. and Grange, J.M., Eds., Tuberculosis: An Interdisciplinary Perspective, Imperial College Press, London, 265-281.

https://doi.org/10.1142/9781848160552_0011 